\title{
Review the bamboo-feeding genus Arcofaciella Fennah, 1956 (Hemiptera: Fulgoromorpha: Delphacidae) with description of a new species from India
}

\author{
Hong-Xing $\mathrm{LI}^{\circledR 1}{ }^{\circledR}$, Xiang-Sheng $\mathrm{CHEN}^{\circledR 2}{ }^{2}$ \& Lin YANG ${ }^{\circledR 3, *}$ \\ ${ }_{1,2,3}$ Institute of Entomology, Guizhou University, Guiyang, Guizhou 550025, P.R. China. \\ ${ }_{1,2,3}$ The Provincial Special Key Laboratory for Development and Utilization of Insect Resources, \\ Guizhou University, Guiyang, Guizhou 550025, P.R. China. \\ ${ }^{1,2,3}$ Guizhou Key Laboratory for Plant Pest Management of Mountainous Region, \\ Guizhou University, Guiyang, Guizhou 550025, P.R. China. \\ *Corresponding author: yanglin6626@163.com \\ 1Email: 1hx5340@163.com \\ ${ }^{2}$ Email: chenxs3218@163.com \\ ${ }^{1}$ urn:1sid:zoobank.org:author:C0D87C71-D577-47AB-BDF7-336177BAA548 \\ ${ }^{2}$ urn:1sid:zoobank.org:author:D9953BEB-30E6-464A-86F2-F325EA2E4B7C \\ ${ }^{3}$ urn:lsid:zoobank.org:author:17FAF564-8FDA-4303-8848-346AB8EB7DE4
}

\begin{abstract}
The planthopper genus Arcofaciella Fennah, 1956 (Hemiptera: Fulgoromorpha: Delphacidae) is reviewed. Four species are recognized, of which A. obflexa Guo \& Liang, 2005 and A. verrucosa Fennah, 1956 are redescribed, and one new species, $A$. indiana sp. nov., is described. Habitus photos for adults and illustrations of male genitalia (excluding A. penangensis (Muir, 1919)) are given. A key for identifying the species of Arcofaciella is also provided.
\end{abstract}

Keywords. Bamboo pests, Fulgoroidea, Oriental region, taxonomy.

Li H.X., Chen X.S. \& Yang L. 2021. Review the bamboo-feeding genus Arcofaciella Fennah, 1956 (Hemiptera: Fulgoromorpha: Delphacidae) with description of a new species from India. European Journal of Taxonomy 748 : 51-66. https://doi.org/10.5852/ejt.2021.748.1341

\section{Introduction}

The planthopper tribe Tropidocephalini Muir, 1915 is the second largest clade of Delphacidae Leach, 1815, mainly occurring in the Oriental region and including approximately 192 species in 37 genera (Chen \& Tsai 2009; Bourgoin 2020). In China, 115 species in 23 genera are known, representing the richest species diversity of this tribe worldwide (Chen 2003; Ding 2006; Qin \& Zhang 2010; Hu \& Ding 2013; Ren et al. 2014; Li et al. 2020). Most Tropidocephalini with reported plant associations feed on bamboo, with all the remaining associated with other grasses (Wilson et al. 1994; Chen 2003; Chen \& Tsai 2009; Qin \& Zhang 2010; Bartlett \& Kennedy 2018). Ren et al. (2014) estimated that many species of the tribe remained undescribed, an interpretation supported by the ongoing descriptions of new endemic species in recent years (Li et al. 2018, 2019a, 2019b, 2019c, 2020). 
Fennah (1956) established the genus Arcofaciella Fennah, 1956 with two species: A. verrucosa Fennah, 1956 (as its type species) from Hong Kong, China, and A. penangensis (Muir, 1919) (previously placed in the genus Acrofacies Muir, 1915 by Muir 1919) from Penang, Malay Peninsula. It belongs to the tribe Tropidocephalini within the subfamily Delphacinae (Hemiptera: Fulgoroidea: Delphacidae). Yang \& Yang (1986) reported $A$. verrucosa from Taiwan. They redescribed the genus and the species and described the fifth instar nymph of $A$. verrucosa for the first time. Liang \& Jiang (2004) recently reported $A$. verrucosa from Fujian and Tibet, China. They redescribed the genus and the species again. Subsequently, Guo et al. (2005) described A. obflexa Guo \& Liang, 2005 from Yunnan, China. So far, this genus includes three species (Muir 1919; Fennah 1956; Liang \& Jiang 2004; Guo et al. 2005).

The aim of this study is to describe a new species of Arcofaciella, to document the first records of Arcofaciella from India, and to provide an identification key for this genus, as well as habitus photos for adults and illustrations of male genitalia for the species (excluding A. penangensis). We also review the genus Arcofaciella. The generic characteristics are redefined and morphological features of these species are either described or redescribed.

\section{Material and methods}

The morphological terminology follows Yang \& Yang (1986). The standard terminology of venation follows Bourgoin et al. (2015). Dry male specimens were used for the description and illustration. External morphology was observed under a stereo microscope and characters were measured with an ocular micrometer. Habitus photos of adults were obtained by the KEYENCE VHX-6000 system. The genital segments of the examined specimens were macerated in $10 \% \mathrm{KOH}$ and drawn from preparations in glycerin jelly using a Leica MZ 12.5 stereo microscope. Illustrations were scanned with a Canon CanoScan LiDE 200 and imported into Adobe Photoshop ver. 6.0 for labeling and plate composition. All the specimens examined are deposited in the Institute of Entomology, Guizhou University, Guiyang, China (GUGC).

\section{Results}

Class Insecta Linnaeus, 1758

Order Hemiptera Linnaeus, 1758

Infraorder Fulgoromorpha Evans, 1946

Family Delphacidae Leach, 1815

Subfamily Delphacinae Leach, 1815

Tribe Tropidocephalini Muir, 1915

Genus Arcofaciella Fennah, 1956

\section{Type species}

Arcofaciella verrucosa Fennah, 1956.

\section{Diagnosis}

Head including eyes (Figs 1G, 2A, 3G, 4A, 5G, 6A) as wide as or wider than pronotum. Vertex (Figs 1G, 2A, 3G, 4A, 5G, 6A) short, trapezoidal; anterior margin transverse, carinate, somewhat incised medially at areolet; posterior margin transverse; lateral margins concave. Frons (Figs 1H, 2C, 3H, 4C, 5H, 6C) at midline longer than wide at widest part, widest above level of ocelli; lateral margins convex; median carina forked at fastigium, areolet weakly depressed. Postclypeus (Figs 2B-C, 4B-C, 6B-C) in lateral view more or less at right angle or obtuse angle to base of frons; in ventral view lateral carinae straight, converging to labrum, median carina absent or present. Rostrum with apex reaching mesotrochanters. Antennae (Figs 1H, 2C, 3H, 4C, 5H, 6C) cylindrical, short, stout, second segment markedly longer 
than first segment, but both together not exceeding length of eye. Pronotum (Figs 1G, 2A, 3G, 4A, $5 \mathrm{G}, 6 \mathrm{~A})$ subequal or longer than vertex along midline, sloping anteriorly and laterally; anteriorly shallowly convex, posteriorly shallowly excavate; median carina distinct, lateral carinae developed only in anterior portion in line with lateral margins of vertex; disc with two pits on each side of median carina. Mesonotum (Figs 1G, 2A, 3G, 4A, 5G, 6A) strongly convex, almost gibbous, strongly sloping laterally and posteriorly, disc tricarinate with lateral carinae feeble. Mesoscutellum (Figs 1G, 2A, 3G, $4 \mathrm{~A}, 5 \mathrm{G}, 6 \mathrm{~A}$ ) distinctly depressed, horizontal, median line of scutum obsolete posteriorly, but present on scutellum, with a distinct groove between scutum and scutellum. Forewings (Figs 2D, 4D, 6D) long, corium enfolding abdomen at region of node, costal margin sinuate, concave distad of node, apical margin shallowly undulate, forks of ScP-R and CuA distad of union of claval veins. Legs relatively short and stout, profemora shorter than procoxae (e.g., Figs 1F, 3F, 5C), hind tibiae with two lateral spines (one very small at base, the other large at about one third from apex) (Fig. 1F) and five teeth at apex; hind tarsomere I with 7, 8 or 9 small even teeth at apex, hind tarsomere II with 5 apical teeth. Anal segment of male (Figs 2E, 4E, 6E) in caudal view ring-like, lateroapical angles weakly protruding caudad or not produced. Pygofer (Figs 2G, 4H, 6G) without medioventral process. Genital styles (Figs 2H-J, $4 \mathrm{I}-\mathrm{J}, 6 \mathrm{H}-\mathrm{I}$ ) long. Aedeagus (Figs $2 \mathrm{~K}-\mathrm{M}, 4 \mathrm{~K}-\mathrm{L}, 6 \mathrm{~J}-\mathrm{K}$ ) with phallotheca. Aedeagus tubular, apical part recurved downward. Phallotheca with valvular process, basal $2 / 3$ quadrate.

\section{Remarks}

This genus is similar to Arcofacies Muir, 1915 but differs from it by: frons with lateral margins distinctly arched (Figs 1H, 2C, 3H, 4C, 5H, 6C) (vs frons with lateral margins subparallel in Arcofacies (Chen et al. 2007: figs 2, 11, 19, 25)); antennae short, obviously not reaching frontoclypeal suture (Figs $1 \mathrm{H}$, $2 \mathrm{C}, 3 \mathrm{H}, 4 \mathrm{C}, 5 \mathrm{H}, 6 \mathrm{C}$ ) (vs antennae long, nearly reaching or surpassing frontoclypeal suture in Arcofacies (Chen et al. 2007: figs 2, 11, 19, 25)); pronotum with lateral carinae not extending to hind margin (Figs 1G, 2A, 3G, 4A, 5G, 6A) (vs pronotum with lateral carinae extending to hind margin in Arcofacies (Chen et al. 2007: figs 1, 10, 18, 24)); spinal formula of hind leg 5-8-5 or 5-9-5 (vs spinal formula of hind leg 5-6-4 in Arcofacies).

\section{Host plant}

Bambusoideae Luerss.

\section{Distribution}

Oriental region (China, Malay Peninsula, India).

\section{Key to species (males) of Arcofaciella Fennah, 1956}

1. Frons in profile inclined anteriorly (Figs 3I, 4B, 5I, 6B); clypeus in profile bent at right angle to frons (Figs 3I, 4B, 5I, 6B), with median carina absent (Figs 4C, 6C)

- Frons in profile not inclined anteriorly (Figs 1I, 2B); clypeus in profile bent at obtuse angle to frons (Figs 1I, 2B), with median carina present (Fig. 2C)

A. indiana sp. nov.

2. Genital styles in posterior view with an angled process medioventrally (Fig. 4I)

A. obflexa Guo \& Liang, 2005

- Genital styles in posterior view without angled process medioventrally (Fig. $6 \mathrm{H})$......................... 3

3. Genital styles in posterior view with hamular process at inner apical laterally (Fig. 6H)

- Genital styles in posterior view with quadrate process at inner apical laterally 


\section{Arcofaciella indiana sp. nov. urn:1sid:zoobank.org:act:7227AA9A-1341-45BA-8F20-EB841BED705D}

Figs $1-2$

\section{Diagnosis}

Arcofaciella indiana sp. nov. can be distinguished from the remaining species of the genus by the frons in profile (Figs 1I, 2B) not inclined anteriorly, the clypeus in profile (Figs 1I, 2B) bent at obtuse angle to frons, the presence of a median carina on the clypeus (Fig. 2C), and the genital styles with inner apical angle not bifurcate (Fig. 2H-J).

\section{Etymology}

This new species is named after the type locality, India.

\section{Type material}

\section{Holotype}

INDIA - ${ }^{\prime}$; Karnataka, Mysore; 12³0' N, 7664' E; 2 Aug. 1972; C.A. Viraktamath leg.; on bamboo; GUGC-FDTA-19720801.

\section{Paratype}

INDIA • 1 + ; same collection data as for holotype; GUGC-FDTA-19720802.

\section{Description}

Measurements. Body length including forewing: male (holotype, GUGC-FDTA-19720801) $4.3 \mathrm{~mm}$ $(\mathrm{N}=1)$; female (paratype, GUGC-FDTA-19720802) $4.6 \mathrm{~mm}(\mathrm{~N}=1)$; forewing length: male (holotype) $3.8 \mathrm{~mm}(\mathrm{~N}=1)$; female (paratype) $4.0 \mathrm{~mm}(\mathrm{~N}=1)$.

Coloration. General color yellowish brown to brown (Fig. 1). Vertex (Fig. 1G) grayish brown, middle area somewhat reddish orange. Frons grayish brown. Clypeus yellow brown. Rostrum yellow brown, distal part black brown. Genae yellow brown to brown. Eyes black brown, ocelli reddish brown. Antennae yellow brown, first segment with distal part and second segment with base part dark brown (Fig. 1H-I). Pronotum grayish brown, middle area somewhat reddish orange, lateral margin brown. Mesonotum grayish brown to brown, intercarinal area somewhat reddish orange (Fig. 1G). Forewings (Fig. 2D) semitransparent, basal half with large inclined yellowish brown stripe, apical half except area between veins ScP and MP ${ }_{1}$ yellowish brown, a small round callus near ScP-R fork and another near $\mathrm{CuA}$ fork piceous, veins brown with yellowish white granules, veins dashed, apex of longitudinal veins brown. Thorax with ventral and lateral areas grayish brown. Legs yellowish brown to brown, with dark brown ring markings.

HEAD AND THORAX. Vertex (Fig. 2A) at midline shorter than wide at base $(0.29: 1)$, width at apex narrower than at base (0.64:1). Frons (Fig. 2C) 1.23 times longer in middle line than widest part, narrower at apex than at base (0.69:1). Antennae (Fig. 2C) with first segment longer than wide at apex (1.25:1), shorter than second segment $(0.48: 1)$. Pronotum (Fig. 2A) at midline slightly shorter than vertex $(0.91: 1)$, lateral carinae arched, medially concave, flexing backwards near middle at sub-right angle and nearly attaining hind margin. Mesonotum (Fig. 2A) 2.82 times as long as vertex and pronotum combined in middle line. Forewing (Fig. 2D) in middle line longer than wide at widest part $(2.75: 1)$. Spinal formula of hind tibia 5-7-5.

Male Genitalia. Anal segment (Fig. 2E) in lateral view small, ring-like, without anal process. Pygofer narrow with ventral margin much longer than dorsal margin in lateral view, laterodorsal angles not produced, posterior lateral margins broadly sinuate (Fig. 2F); in posterior view with opening longer 

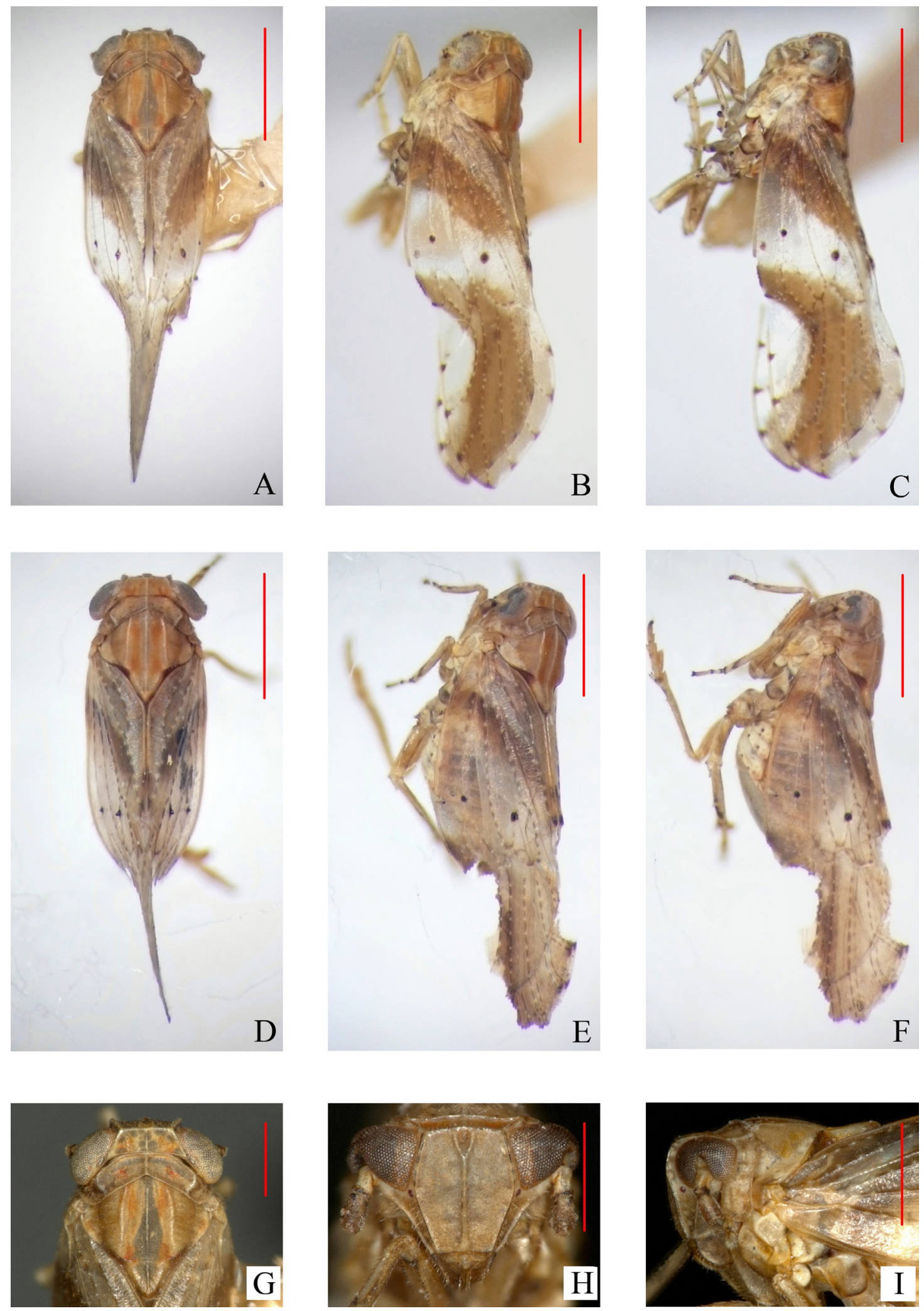

Fig. 1. Arcofaciella indiana sp. nov. A-C, G-I = holotype, ô (GUGC-FDTA-19720801), D-F = paratype, q (GUGC-FDTA-19720802). A. Male habitus, dorsal view. B-C. Same, lateral view. D. Female habitus, dorsal view. E-F. Same, lateral view. G. Head and thorax, dorsal view. H. Face. I. Frons, lateral view. Scale bars: A-F $=1 \mathrm{~mm} ; \mathrm{G}-\mathrm{I}=0.5 \mathrm{~mm}$. 

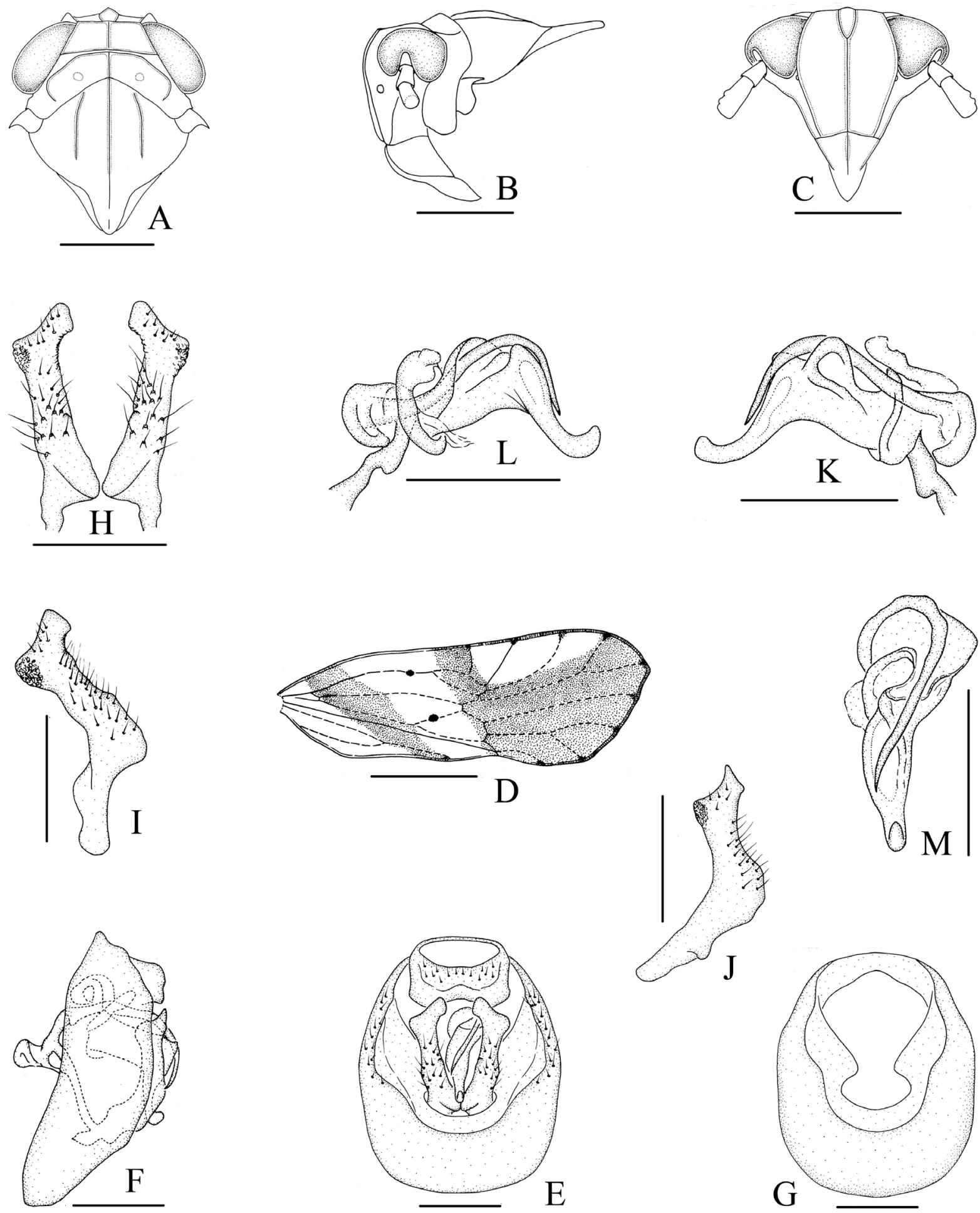

Fig. 2. Arcofaciella indiana sp. nov., holotype, ô (GUGC-FDTA-19720801). A. Head and thorax, dorsal view. B. Same, lateral view. C. Face. D. Forewing. E. Male genitalia, posterior view. F. Same, lateral view. G. Pygofer, posterior view. H. Genital style, posterior view. I. Same, posterior and lateral views. J. Same, lateral view. K. Aedeagus, right lateral view. L. Same, left lateral view. M. Same, dorsal view. Scale bars: $\mathrm{A}-\mathrm{C}=0.5 \mathrm{~mm} ; \mathrm{D}=1 \mathrm{~mm}$; $\mathrm{E}-\mathrm{M}=0.2 \mathrm{~mm}$. 
than wide, lateral margin thick and not well defined, medioventral process absent (Fig. 2G). Genital styles (Fig. 2H-J) long, reaching basal anal segment, apical part distinctly curved inward, outer apical angle rounded and protruding slightly dorsad, inner apical angle quadrate, with inner edge angularly directed dorsally in lateral view. Aedeagus (Fig. 2K-M) long, tubular, with distinct phallotheca, with basal part lying between two valvular processes of phallotheca, deflecting leftward, apical part recurved downward and reaching $2 / 3$ of phallotheca. Phallotheca almost reaching base of genital styles, apical part warping dorsad, basal part stout, with two valvular processes, in dorsal view with a large and a small round valvular processes, tapering from $1 / 2$ to apex, in right view with three processes near base.

\section{Host plant}

Bambusoideae.

\section{Distribution}

India (Karnataka).

\section{Remarks}

This species is similar to A. obflexa Guo \& Liang, 2005 in having a similar shape of the frons, in the cylindrical antennae, in the relatively larger pronotum, in the gibbous mesonotum, strongly sloping laterally and posteriorly, and in the shape of the forewing. However, it can be distinguished from the latter by the following features: (1) frons in profile (Figs 1I, 2B) not inclined anteriorly (vs frons in profile (Figs 3I, 4B) inclined anteriorly in A. obflexa); (2) clypeus in profile (Figs 1I, 2B) bent at obtuse angle to frons, with median carina present (vs clypeus in profile (Figs 3I, 4B) bent at right angle to frons, with median carina obsolete in A. obflexa); (3) spinal formula of hind tibia 5-7-5 (vs spinal formula of hind tibia 5-8-5 in A. obflexa); (4) anal segment of male (Fig. 2E) with lateroapical angles without spinous process (vs anal segment of male (Fig. 4E) with lateroapical angles produced into stout spinous process caudad in A. obflexa); (5) genital styles (Fig. 2H-J) without angled process medioventrally, inner apical angle not bifurcate (vs genital styles (Fig. 4I-J) with an angled process medioventrally, inner apical angle bifurcate in $A$. obflexa).

This species is also similar to $A$. verrucosa Fennah, 1956 in having a similar shape of the frons, in the cylindrical antennae, in the relatively larger pronotum, in the gibbous mesonotum, strongly sloping laterally and posteriorly, and in the shape and similar color of the forewing. However, it can be distinguished from the latter by the following features: (1) frons in profile (Figs 1I, 2B) not inclined anteriorly (vs frons in profile (Figs 5I, 6B) inclined anteriorly in A. obflexa); (2) clypeus in profile (Figs 1I, 2B) bent at obtuse angle to frons, with median carina present (vs clypeus in profile (Figs 5I, 6B) bent at right angle to frons, with median carina obsolete in A. verrucosa); (3) spinal formula of hind tibia 5-7-5 (vs spinal formula of hind tibia 5-8-5 or 5-9-5 in A. verrucosa); (4) genital styles (Fig. 2H-J) with inner apical angle not bifurcate (vs genital styles (Fig. 6H-I) with inner apical angle bifurcate in A. obflexa).

Arcofaciella obflexa Guo \& Liang, 2005

Figs $3-4$

\section{Material examined}

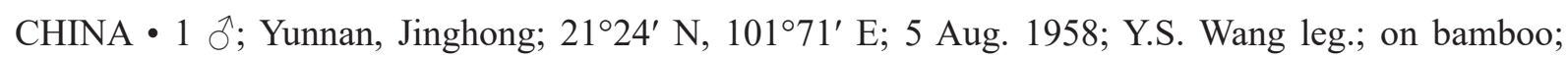

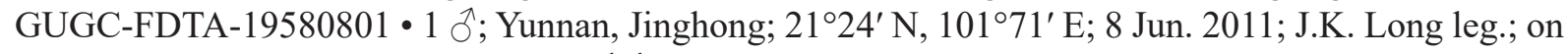

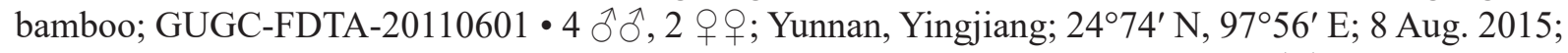

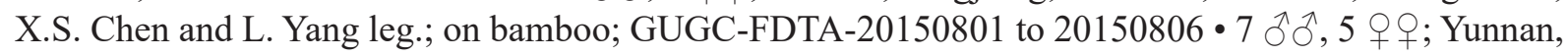
Yingjiang; 2474' N, 9756' E; 19 Aug. 2018; H.X. Li, F.E. Li and Q. Luo leg.; on bamboo; GUGC- 

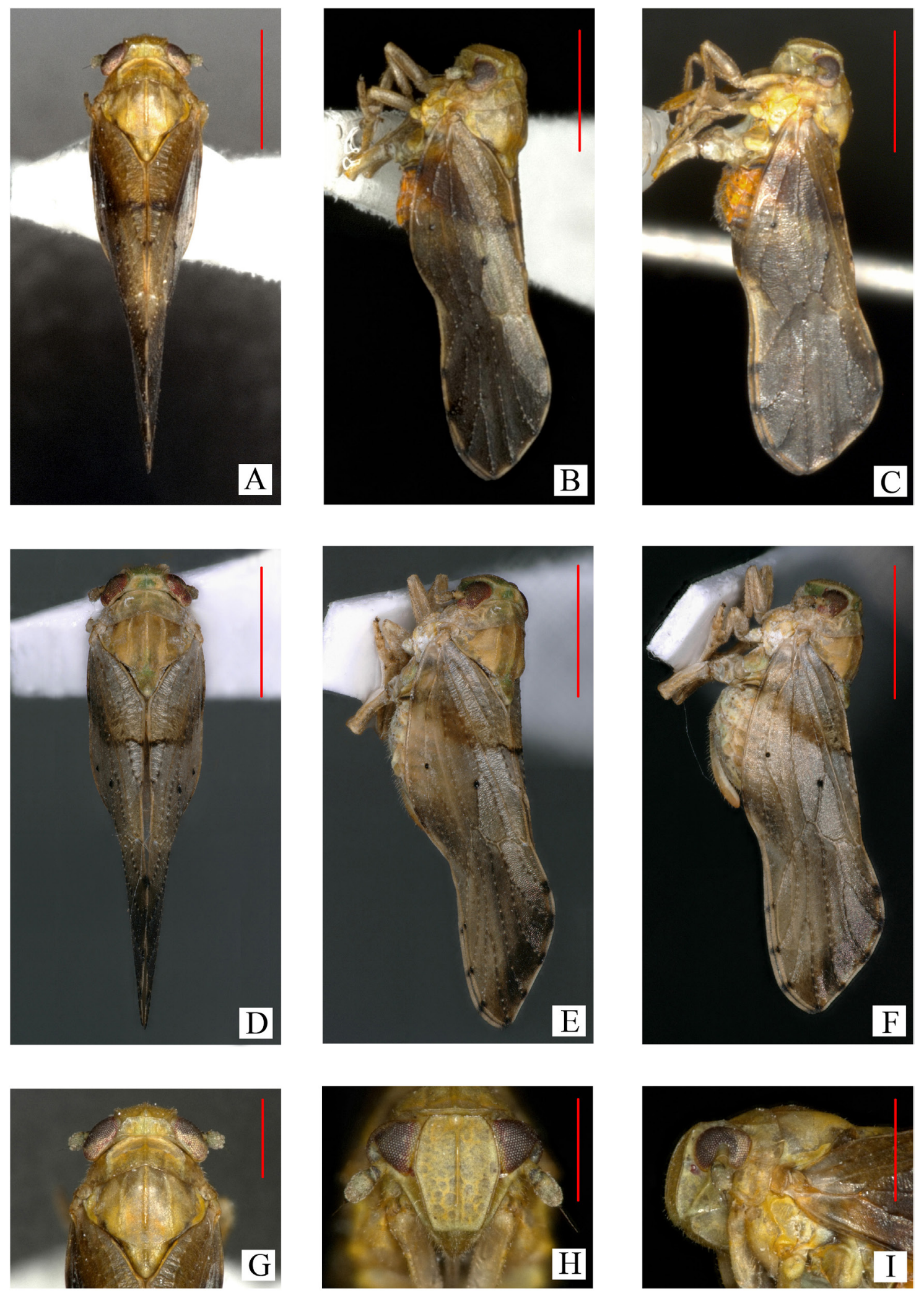

Fig. 3. Arcofaciella obflexa Guo \& Liang, 2005. A-C, G-I = § (GUGC-FDTA-20190601); D-F = 9 (GUGC-FDTA-20190602). A. Male habitus, dorsal view. B-C. Same, lateral view. D. Female habitus, dorsal view. E-F. Same, lateral view. G. Head and thorax, dorsal view. H. Face. I. Frons, lateral view. Scale bars: A-F $=1 \mathrm{~mm}$; $\mathrm{G}-\mathrm{I}=0.5 \mathrm{~mm}$. 

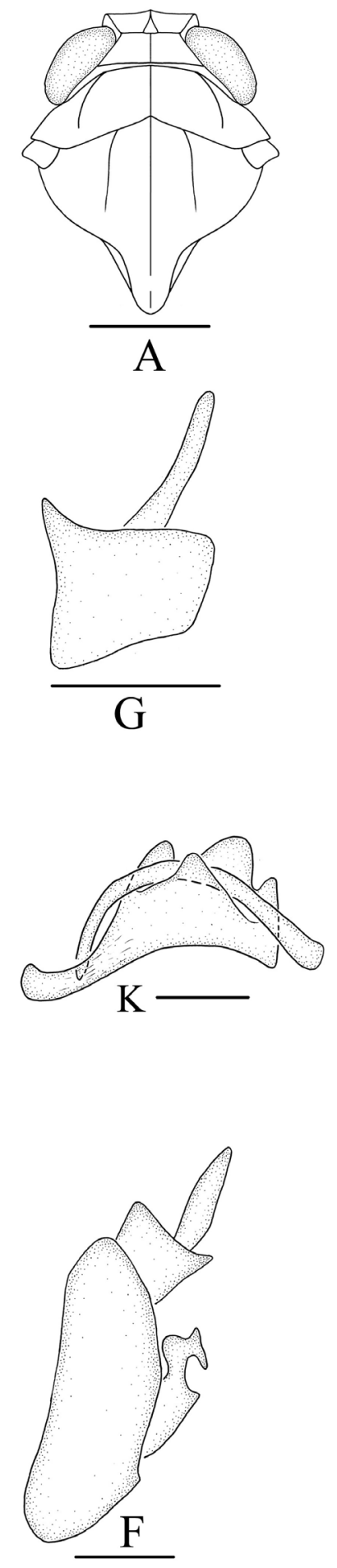
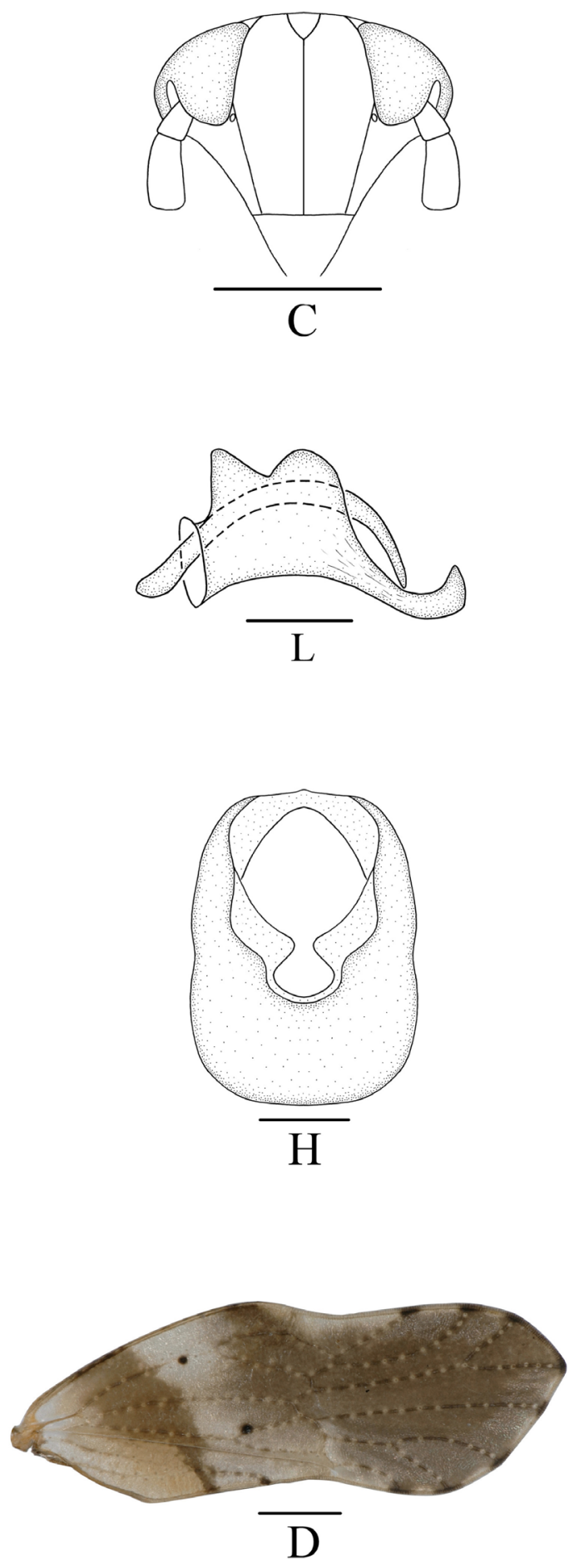
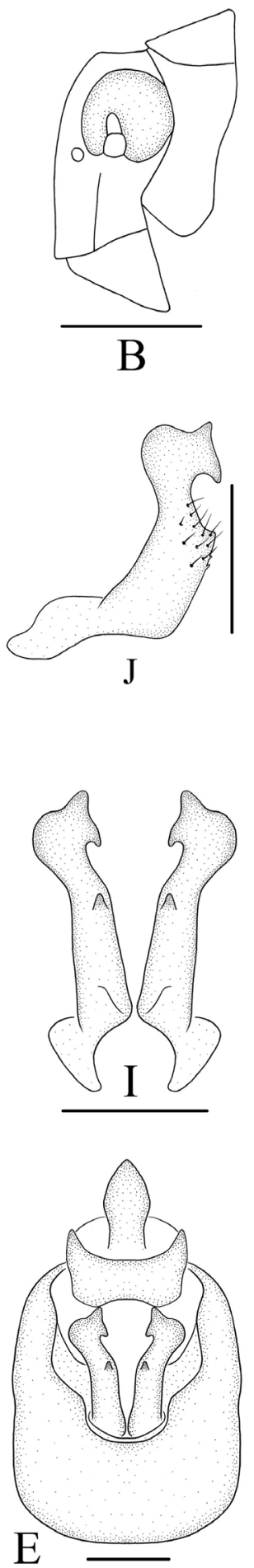

Fig. 4. Arcofaciella obflexa Guo \& Liang, 2005, ô (GUGC-FDTA-20190601). A. Head and thorax, dorsal view. B. Same, lateral view. C. Face. D. Forewing. E. Male genitalia, posterior view. F. Same, lateral view. G. Anal segment, lateral view. H. Pygofer, posterior view. I. Genital style, posterior view. J. Same, lateral view. K. Aedeagus, right lateral view. L. Same, left lateral view. Scale bars: A-D = $0.5 \mathrm{~mm}$; $-\mathrm{J}=0.2 \mathrm{~mm} ; \mathrm{K}-\mathrm{L}=0.1 \mathrm{~mm}$. 


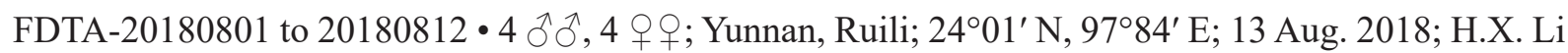

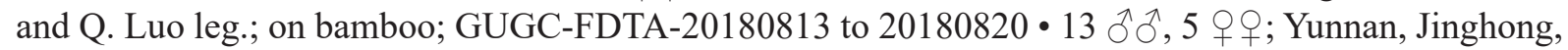
Menglong; $21^{\circ} 57^{\prime}$ N, $100^{\circ} 67^{\prime}$ E; 21 Jun. 2019; H.X. Li, S.Y. Xun, N. Gong and F.E. Li leg.; on bamboo; GUGC-FDTA-20190601 to 20190618.

\section{Redescription}

Measurements. Body length including forewing: male 4.3-4.6 $\mathrm{mm}(\mathrm{N}=10)$; female $4.5-4.9 \mathrm{~mm}(\mathrm{~N}=$ 10); forewing length: male 3.6-3.8 $\mathrm{mm}(\mathrm{N}=10)$; female 3.7-4.0 $\mathrm{mm}(\mathrm{N}=10)$.

Coloration. Vertex (Fig. 3G), face (Fig. 3H) yellowish green. Antennae (Fig. 3H) light scorched green, distal part of first segment and basal part of second segment black brown. Pronotum (Fig. 3G), mesonotum (Fig. 3G) and legs scorched, abdomen light nacarat, slightly lighter ventrally and disc of first abdominal segment black. Forewings (Fig. 4D) grayish brown, darker at base, veins brown with yellowish white granules, veins dashed, apex of longitudinal veins brown.

HEAD AND THORAX. Vertex (Fig. 4A) at midline shorter than wide at base $(0.28: 1)$, width at apex narrower than at base (0.56:1). Frons (Fig. 4C) 1.35 times longer in middle line than widest part, narrower at apex than at base (0.86:1). Postclypeus wider at base than frons at apex. Antennae (Fig. 4C) with first segment longer than wide at apex $(1.33: 1)$, shorter than second segment $(0.63: 1)$. Pronotum (Fig. 4A) at midline longer than vertex $(1.71: 1)$, lateral carinae arched, medially concave, flexing backwards near middle at sub-right angle and nearly attaining hind margin. Mesonotum (Fig. 4A) 2.39 times as long as vertex and pronotum combined in middle line. Forewing (Fig. 4D) in middle line longer than wide at widest part (3.12:1). Spinal formula of hind tibia 5-8-5.

Male Genitalia. Anal segment in posterior view (Fig. 4E) concave medially, lateroapical angle protruding caudad, anal style distinctly elongate and narrow, nearly lanceolate in lateral view (Fig. 4G). Pygofer in profile (Fig. 4F) with dorsal margin shorter than ventral margin, posterior margin convex, in posterior view (Fig. 4H) with opening longer than wide, ventral margin broadly concave, without medioventral process. Genital styles (Fig. 4I-J) long, reaching basal anal segment, with an angled process medioventrally and 2 small teeth at outer base laterally, apex with outer apical angle rounded and protruding, slightly dorsad, inner apical angle bifurcate, inner laterodorsal margin with a dull angled process at $2 / 3$ of genital styles near base. Aedeagus (Fig. 4K-L) long, tubular, with distinct phallotheca, with basal part lying between two valvular processes of phallotheca, deflecting leftward, apical part recurved downward and reaching $2 / 3$ of phallotheca. Phallotheca almost reaching base of genital styles, apical part warping dorsad, basal part stout, with two valvular processes, in dorsal view with a large and a small round valvular processes, tapering from $3 / 5$ to apex, in right view with three processes near base.

\section{Host plant}

Bambusoideae.

\section{Distribution}

China (Yunnan).

\section{Material examined}

Arcofaciella penangensis (Muir, 1919)

No specimen has been collected by the authors.

\section{Description}

The description and illustration are reproduced from Muir (1919). 
Measurements. "Body length: male $2.1 \mathrm{~mm}$, female $2.8 \mathrm{~mm}$; forewing length: male $3.6 \mathrm{~mm}$, female $4.4 \mathrm{~mm} "$.

Coloration. "Male ochraceous buff; hind legs slightly fuscous, abdomen bright yellow with a few, small, black spots on sternites, chestnut brown over pygophor and genital styles; forewings chestnut brown, darkest over basal third, a clearer space along middle of costa at the emargination, a dark mark at apex of each apical vein, a small one at apex of claval vein, at fork of cubitus and fork of subcosta and radius, veins the same color as membrane, with numerous small, light granules. Female with forewings lighter than in male, abdomen ochraceous with a small black spot on each sternite, ovipositor same color as pygofer".

HEAD AND THORAX. "Width of vertex at base double the length, base nearly double the width of apex; length of face 1.5 times the width, sides slightly arcuate; antennae not reaching base of clypeus, second joint 1.5 times length of first. In lateral view the clypeus at right angle to face, apex of face projecting slightly beyond clypeus; mesonotum considerably arched. Hind femora short, not reaching beyond apex of abdomen; tibiae longer than femora, tarsi much shorter than tibiae, first tarsus subequal in length to other two together, spur small, about as long as first tarsus, fairly broad, thick, a tooth at apex but none on hind margin. Forewings acutely tectiform, compressed beyond apex of abdomen, costal margin shallowly emarginated beyond apex of abdomen, apex acute".

MALE Genitalia. "Pygopher round with a small opening, no distinct dorsal emargination, anal segment short, exposed, without spines, anal style large, lanceolate; genital styles slightly curved, flattened, margins subparallel, apex truncate and produced into a quadrate process on inner margin".

\section{Host plant}

Unknown.

\section{Distribution}

Malay Peninsula (Penang).

Arcofaciella verrucosa Fennah, 1956

Figs 5-6

\section{Material examined}

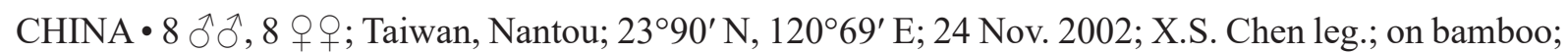

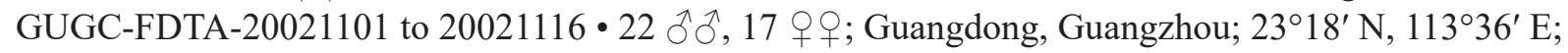
22 Nov. 2006; X.S. Chen leg.; on bamboo; GUGC-FDTA-20061101 to 20061139 - 14 ठึ Hunan, Xinning, Langshan; 26 $43^{\prime} \mathrm{N}, 110^{\circ} 85^{\prime} \mathrm{E}$; 10 Aug. 2007; X.S. Chen leg.; on bamboo; GUGC-

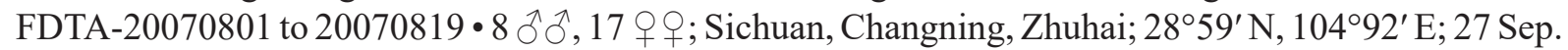
2008; H.R. Li leg.; on bamboo; GUGC-FDTA-20080901 to 20080925・1 $\partial^{\lambda}, 11$ 우; Sichuan, Changning, Sansong; $28^{\circ} 56^{\prime}$ N, $104^{\circ} 92^{\prime}$ E; 28 Sep. 2008; H.R. Li leg.; on bamboo; GUGC-FDTA-20080926 to 20080937 • 3 o $^{\wedge} \mathrm{o}^{\prime}$; Guangdong, Zhuhai; $22^{\circ} 20^{\prime} \mathrm{N}, 113^{\circ} 29^{\prime}$ E; 9 Oct. 2008; X.H. Hou leg.; on bamboo; GUGC-FDTA-20081001 to $20081003 \cdot 1$ ơ; Hainan, Haikou, Huoshankou; $19^{\circ} 92^{\prime} \mathrm{N}, 110^{\circ} 21^{\prime} \mathrm{E}$; 8 Apr. 2009; X.H. Hou leg.; on bamboo; GUGC-FDTA-20090401 • 2 + + ; Guangxi, Daxin, Enchen; $22^{\circ} 81^{\prime} \mathrm{N}, 107^{\circ} 19^{\prime} \mathrm{E}$; 4 May 2009; H.R. Li leg.; on bamboo; GUGC-FDTA-20090501 to 20090502

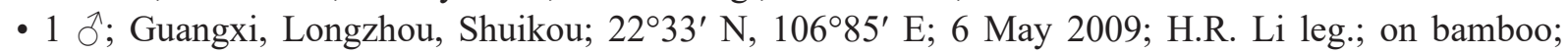

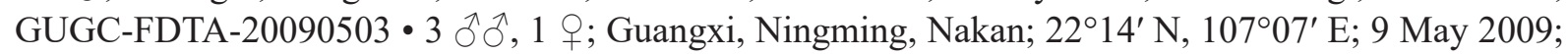

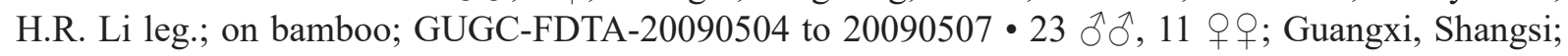
$22^{\circ} 15^{\prime}$ N, $107^{\circ} 98^{\prime}$ E; 11 May 2009; H.R. Li leg.; on bamboo; GUGC-FDTA-20090508 to 20090541 
- $3 \widehat{\partial}^{\widehat{\partial}}$, 4 우; Guangxi, Shuoyang, Baisha; $23^{\circ} 73^{\prime} \mathrm{N}, 1^{106^{\circ}} 9^{\prime}$ E; 20 May 2009; on bamboo; GUGC-

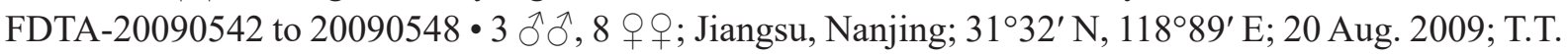
He leg.; on bamboo; GUGC-FDTA-20090801 to 20090811 • 41 §ิ $\widehat{\jmath}, 57$ 우; Guangdong, Guangzhou; $23^{\circ} 18^{\prime}$ N, 113³6' E; 22 Aug. 2010; X.H. Hou leg.; on bamboo; GUGC-FDTA-20100801 to 20100898

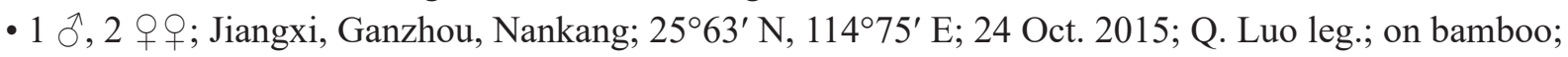

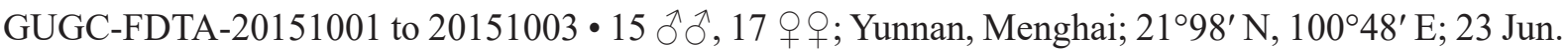
2019; H.X. Li, N. Gong and F.E. Li leg.; on bamboo; GUGC-FDTA-20190619 to 20190650 • 18 §ð,

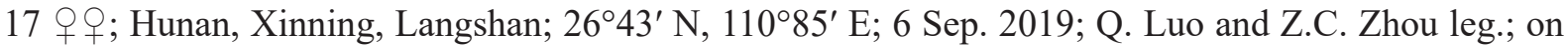
bamboo; GUGC-FDTA-20190901 to 20190935.

\section{Redescription}

MeAsurements. Body length including forewing: male 4.3-4.5 $\mathrm{mm}(\mathrm{N}=10)$; female $4.8-5.1 \mathrm{~mm}(\mathrm{~N}=$ 10); forewing length: male 3.5-3.7 $\mathrm{mm}(\mathrm{N}=10)$; female 3.5-4.6 $\mathrm{mm}(\mathrm{N}=10)$.

Coloration. General color greenish stramineous (Fig. 5); two spots on vertex and impression in fork of median carina of frons orange (Fig. 5G). Forewings (Fig. 6D) translucent-ochraceous, a small round callus near ScP-R fork and another near $\mathrm{CuA}$ fork piceous, a faint transverse stripe across middle of clavus, and apical veins at margin brown. Hindwings yellowish hyaline, veins concolorous. Abdomen light nacarat, slightly lighter ventrally, and disc of first abdominal segment ventrally and dorsally black.

HEAD AND THORAX. Vertex (Fig. 6A) at midline shorter than wide at base $(0.27: 1)$, width at apex narrower than at base (0.58:1). Frons (Fig. 6C) 1.44 times longer in middle line than widest part, narrower at apex than at base (0.95:1). Postclypeus (Fig. 6C) wider at base than frons at apex. Antennae (Fig. 6C) with first segment longer than wide at apex (1.08:1), shorter than second segment $(0.52: 1)$. Pronotum (Fig. 6A) at midline longer than vertex (1.53:1). Mesonotum (Fig. 6A) 3.74 times as long as vertex and pronotum combined in middle line. Forewing (Fig. 6D) in middle line longer than wide at widest part (3.12:1). Spinal formula of hind tibia 5-8-5 or 5-9-5.

Male Genitalia. Anal segment (Fig. 6E) moderately large, ring-like, without anal process, anal style distinctly elongate and narrow, nearly lanceolate in lateral view (Fig. 6F). Pygofer in profile (Fig. 6F) with dorsal margin shorter than ventral margin, posterior margin convex, in posterior view (Fig. 6G) with opening longer than wide, ventral margin broadly concave, without medioventral process. Genital styles (Fig. 6H-I) long, reaching basal anal segment, laterally compressed, nearly paralleled, in posterior view (Fig. 6H) with outer apical angle rounded, inner apical angle bifurcate, in lateral view (Fig. 6I) with upper $2 / 5$ with posterior edge excavated, apical part distinctly curved inward, with inner edge angularly directed ventrally. Aedeagus (Fig. 6J-K) long, tubular, with distinct phallotheca, with basal part lying between two valvular processes of phallotheca, deflecting leftward, apical part recurved downward and reaching $2 / 3$ of phallotheca. Phallotheca shaft laterally compressed, narrowing distad and strongly deflexed, recurved caudad at blunt apex.

\section{Host plant}

Bambusa dolichoclada Hayata, B. oldhamii Munro, B. multiplex (Lour.) Raeusch., B. multiplex cv. fernleaf Rob.A.Young, B. multiplex cv. Alphonse Karr Rob.A.Young (Bambusoideae).

\section{Distribution}

China (Hong Kong, Taiwan, Fujian, Tibet, Hunan, Guangdong, Sichuan, Hainan, Guangxi, Jiangsu, Jiangxi, Guizhou, Yunnan). 

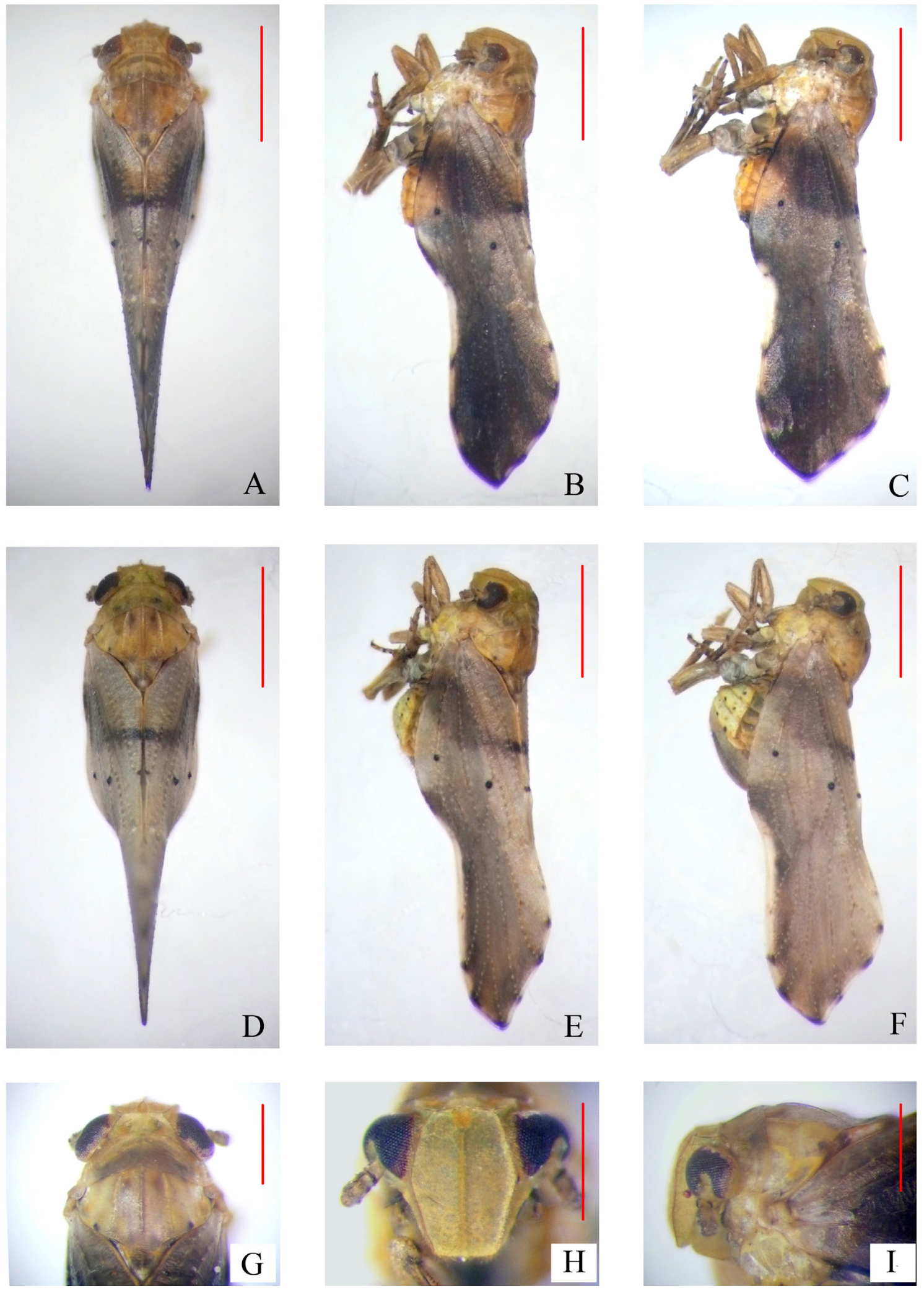

Fig. 5. Arcofaciella verrucosa Fennah, 1956. A-C, G-I = § (GUGC-FDTA-20190619); D-F = ㅇ (GUGC-FDTA-20190620). A. Male habitus, dorsal view. B-C. Same, lateral view. D. Female habitus, dorsal view. E-F. Same, lateral view. G. Head and thorax, dorsal view. H. Face. I. Frons, lateral view. Scale bars: A-F $=1 \mathrm{~mm}$; $\mathrm{G}-\mathrm{I}=0.5 \mathrm{~mm}$. 

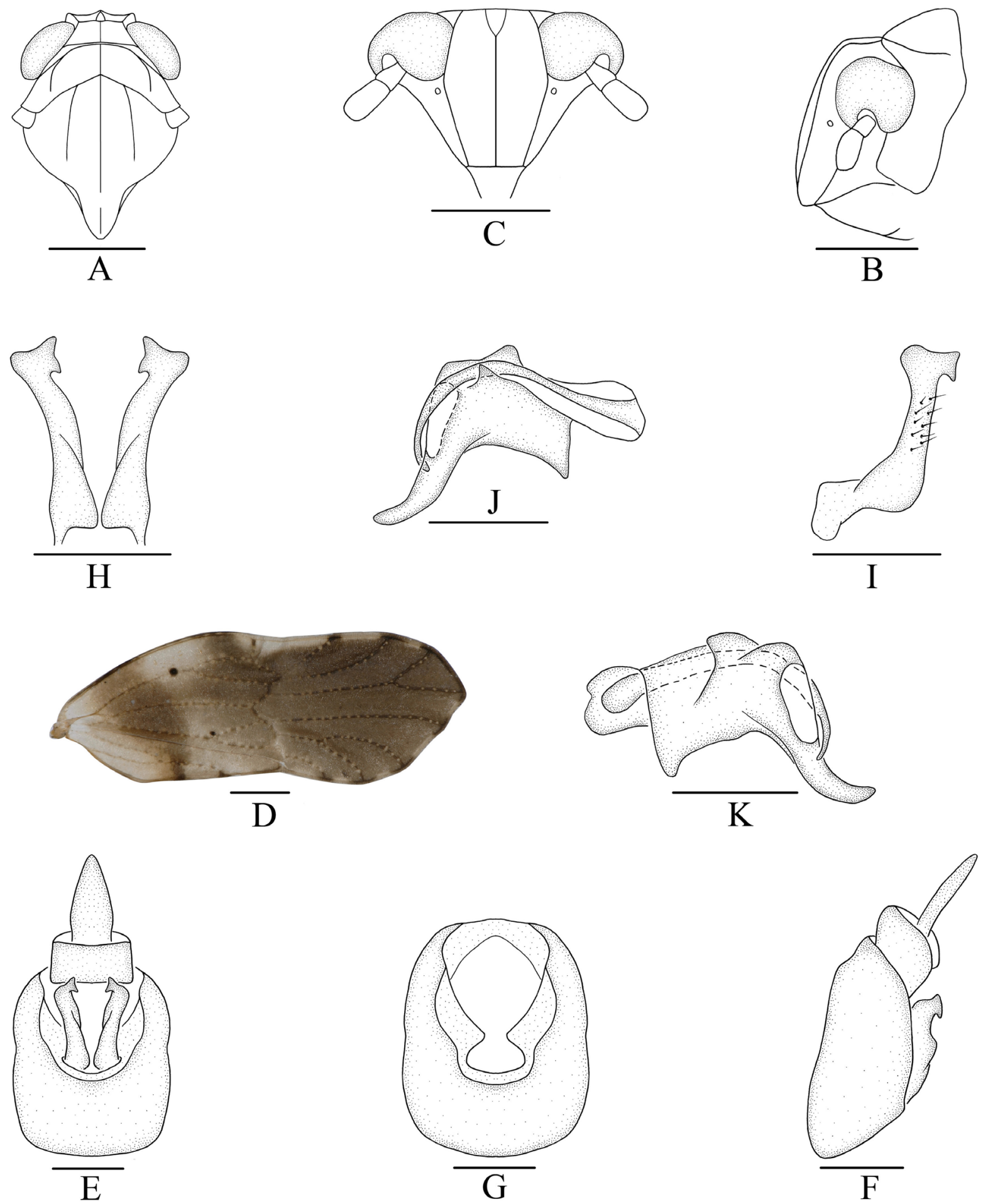

Fig. 6. Arcofaciella verrucosa Fennah, 1956, ô (GUGC-FDTA-20190619). A. Head and thorax, dorsal view. B. Same, lateral view. C. Face. D. Forewing. E. Male genitalia, posterior view. F. Same, lateral view. G. Pygofer, posterior view. H. Genital style, posterior view. I. Same, lateral view. J. Aedeagus, right lateral view. $\mathbf{K}$. Same, left lateral view. Scale bars: A-D =0.5 mm; E-K=0.2 mm. 


\section{Discussion}

The Chinese fauna of Tropidocephalini represents the richest species diversity of this tribe worldwide. Recent increased interest in the Chinese fauna will undoubtedly turn up many other important new discoveries. There are at least five delphacid taxa in the Tropidocephalini from China that appear to be undescribed and are intended as subjects of future work. Previously, the investigation and collection of delphacid taxa in China were mostly concentrated in the southern provinces. Further survey of delphacid taxa should be carried out to the other regions in China.

\section{Acknowledgments}

The authors are grateful to Dr C.A. Viraktamath (Department of Entomology, University of Agricultural Sciences, GKVK, Bengaluru, India) for providing specimens and professor A.P. Liang (Key Laboratory of Zoological Systematics and Evolution, Institute of Zoology, Chinese Academy of Sciences, Beijing, China) for transferring the specimens. We also are grateful to the other specimen collectors for their hard work in the field collections. This work was supported by the National Natural Science Foundation of China (No. 32060343, 31472033, 31601886); the Science and Technology Support Program of Guizhou Province (No. 20201Y129); the Program of Excellent Innovation Talents, Guizhou Province (No. 20154021); the Science and Technology Program of Guizhou Province (No. 20181031) and the Program of Scientific Research Foundation for Introduced Talent of Guizhou University (No. 201718).

\section{References}

Bartlett C.R. \& Kennedy A.C. 2018. A review of New World Malaxa (Hemiptera: Fulgoroidea: Delphacidae). Zootaxa 4441 (3): 511-528. https://doi.org/10.11646/zootaxa.4441.3.5

Bourgoin T. 2020. FLOW (Fulgoromorpha Lists on the Web): a world knowledge base dedicated to Fulgoromorpha. Available from http:/hemiptera-databases.org/flow [accessed 20 May 2020].

Bourgoin T., Wang R.R., Asche M., Hoch H., Soulier-Perkins A., Stroinski A., Yap S. \& Szwedo J. 2015. From micropterism to hyperpterism: recognition strategy and standardized homology-driven terminology of the forewing venation patterns in planthoppers (Hemiptera: Fulgoromorpha). Zoomorphology 134 (1): 63-77. https://doi.org/10.1007/s00435-014-0243-6

Chen X.S. 2003. Key to genera of the tribe Tropidocephalini from the People's Republic of China with description of a new genus. The Canadian Entomologist 135: 811-821. https://doi.org/10.4039/n02-097

Chen X.S. \& Tsai J.H. 2009. Two new genera of Tropidocephalini (Hemiptera: Fulgoroidea: Delphacidae) from Hainan Province, China. Florida Entomologist 92 (2): 261-268.

https://doi.org/10.1653/024.092.0210

Chen X.S., Yang L. \& Tsai H.J. 2007. Review of the Bamboo delphacid genus Arcofacies (Hemiptera: Fulgoroidea: Delphacidae) from China, with description of one new species. Florida Entomologist 90 (4): 683-689. https://doi.org/10.1653/0015-4040(2007)90[683:ROTBDG]2.0.CO;2

Ding J.H. 2006. Fauna Sinica Insecta Vol. 45 Homoptera Delphacidae. Science Press, Beijing.

Fennah R.G. 1956. Fulgoroidea from southern China. California Academy Sciences 28 (4): 441-527.

Guo L.Z., Liang A.P. \& Jiang G.M. 2005. Four new species and a new record of Delphacidae (Hemiptera) from China. Oriental Insects 39: 161-174. https://doi.org/10.1080/00305316.2005.10417430

Hu C.L. \& Ding J.H. 2013. One new genus and species of Tropidocephalini (Hemiptera, Delphacidae, Delphacinae) from Tibet, China. Acta Zootaxonomica Sinica 38 (3): 552-555. 
Liang A.P. \& Jiang G.M. 2004. Discovery of the genus Arcofaciella Fennah (Hemiptera: Fulgoroidea: Delphacidae) in mainland China. Journal of the New York Entomological Society 112 (4): 221-226. https://doi.org/10.1664/0028-7199(2004)112[0221:DOTGAF]2.0.CO;2

Li H.X., Yang L. \& Chen X.S. 2018. Two new species of the bamboo-feeding planthopper genus Bambusiphaga Huang \& Ding from China (Hemiptera, Fulgoromorpha, Delphacidae). ZooKeys 735: 83-96. https://doi.org/10.3897/zookeys.735.21727

Li H.X., Yang L. \& Chen X.S. 2019a. Two new species of the bamboo-feeding planthopper genus Purohita Distant from China (Hemiptera, Fulgoromorpha, Delphacidae). ZooKeys 855: 85-94. https://doi.org/10.3897/zookeys.855.31561

Li H.X., Yang L. \& Chen X.S. 2019b. Taxonomic study of the genus Malaxa Melichar, with descriptions of two new species from China (Hemiptera, Fulgoroidea, Delphacidae). ZooKeys 861: 43-52. https://doi.org/10.3897/zookeys.861.32777

Li H.X., Yang L. \& Chen X.S. 2019c. Two new species of the bamboo-feeding planthopper genus Arcofacies Muir (Hemiptera: Fulgoroidea: Delphacidae) from China. Zootaxa 4706 (2): 384-390. https://doi.org/10.11646/zootaxa.4706.2.11

Li H.X., Yang L. \& Chen X.S. 2020. Two new species of the bamboo-feeding planthopper genus Neobelocera Ding \& Yang, 1986 from China (Hemiptera, Fulgoroidea, Delphacidae). European Journal of Taxonomy 641: 1-14. https://doi.org/10.5852/ejt.2020.641

Muir F.A.G. 1919. Some Malayan Delphacidae (Homoptera). Philippine Journal of Science 15 (6): $521-531+$ plate 1 .

Qin D.Z. \& Zhang Y.L. 2010. A key to the genera of Tropidocephalini (Hemiptera: Fulgoromorpha: Delphacidae) of China with description of Mucillnata rava, new genus and species. Zootaxa 2448: 61-68. https://doi.org/10.11646/zootaxa.2448.1.5

Ren F.J., Zheng L.F., Huang Y.X. \& Qin D.Z. 2014. Lauriana Ren \& Qin, a new genus of the tribe Tropidocephalini (Hemiptera: Fulgoromorpha: Delphacidae) from China. Zootaxa 3784: 84-88. https://doi.org/10.11646/zootaxa.3784.1.6

Wilson S.W., Mitter C., Denno R.F. \& Wilson M.R. 1994. Evolutionary patterns of host plant use by delphacid planthoppers and their relatives. In: Denno R.F. \& Perfect T.J. (eds) Planthoppers: Their Ecology and Management: 7-45. Chapman and Hall, New York.

https://doi.org/10.1007/978-1-4615-2395-6_2

Yang J.T. \& Yang C.T. 1986. Delphacidae of Taiwan (I) Asiracinae and the tribe Tropidocephalini (Homoptera: Fulgoroidea). Taiwan Museum Special Publication Series 6: 29-34.

Manuscript received: 10 June 2020

Manuscript accepted: 3 March 2021

Published on: 4 May 2021

Topic editor: Nesrine Akkari

Section editor: Christopher H. Dietrich

Desk editor: Radka Rosenbaumová

Printed versions of all papers are also deposited in the libraries of the institutes that are members of the EJT consortium: Muséum national d'histoire naturelle, Paris, France; Meise Botanic Garden, Belgium; Royal Museum for Central Africa, Tervuren, Belgium; Royal Belgian Institute of Natural Sciences, Brussels, Belgium; Natural History Museum of Denmark, Copenhagen, Denmark; Naturalis Biodiversity Center, Leiden, the Netherlands; Museo Nacional de Ciencias Naturales-CSIC, Madrid, Spain; Real Jardín Botánico de Madrid CSIC, Spain; Zoological Research Museum Alexander Koenig, Bonn, Germany; National Museum, Prague, Czech Republic. 